\title{
GEOGRAPHIC VARIATION IN BODY SIZE AND ITS RELATION TO THE MATING STRUCTURE OF TETRAOPES POPULATIONS
}

\author{
DAVID E. MCCAULEY \\ Department of Biology, The University of Chicago, 1103 E. 57th Street, \\ Chicago, Illinois, U.S.A. 60637
}

Received 13.ix.78

\begin{abstract}
SUMmary
Adult milkweed beetles (genus Tetraopes) are shown to exhibit geographical variation in the intensity of stabilising selection on body size. This is related in both sexes to inter-locality variation in the amount of intrapopulational variability present in this character. Mean size of female beetles also varies geographically. A model of the selection process is proposed that would select against migration between locally differentiated populations and preserve the partitioning of genetic variation among these populations.
\end{abstract}

\section{InTRODUGTION}

BoDy size in the milkweed beetle Tetraopes tetraophthalmus (Coleoptera: Cerambycidae) has been shown previously to be under strong stabilising selection with regards to mating fitness (Mason, 1964; Scheiring, 1977). Adult beetles of extreme body size were found to be either less successful at obtaining mates or less capable of mating for extended periods of time than were intermediate sized beetles. The present study seeks to examine the constancy of this phenomenon across five localities in the eastern half of the species' range by comparing the variance in the size of those individuals found mating to that of unpaired beetles collected at each site. Variance within and between populations for body size was measured and compared to the intensity of stabilising selection. Using the empirical data, a fitness function can be calculated relating body size to mating success within populations. This can then be used to predict the relative fitnesses of individuals migrating among populations differing in their mean body size.

\section{MAterials AND MEthodS}

Tetraopes were collected in June and July of 1978 at the five localities shown in table 1. Collections were made by moving through the milkweed field so as to minimise disturbance, and collecting both solitary individuals

\section{TABLE 1}

The location of sampled populations of Tetraopes tetraophthalmus

Locality number

1

2

3

4

5
Site

Du Page Co., Illinois

Du Page Co., Illinois

Montgomery Co., Indiana

McCreary Co., Kentucky

Queen Anne's Co., Maryland 
and mating pairs until a sufficiently large sample size was obtained. Prior to disturbance about 25 per cent of the adults present were typically found mating on the leaves and flowerheads of the milkweed plants. It was felt that collections made in this way allowed a nearly instantaneous random time slice to be taken of the mating behaviour of an undisturbed population. Those size classes with a mating advantage would be expected to be found in copula at a frequency in excess of their overall frequency. Phenotypes with a mating disadvantage should be over-represented in the unpaired class. Localities were selected that consisted of large isolated patches of the milkweed Asclepias syriaca along a rough transect from Chicago, Illinois to the mid-Atlantic coast of the U.S.A. Only localities in which at least thirty mating pairs were captured are used in the present analysis. Body size was estimated by measuring elytral length with a binocular microscope fitted with an ocular micrometer. This character was considered by both Mason (1964) and Scheiring (1977) to be a good indicator of overall body size. Statistical methods will be presented with the data.

\section{Results}

Estimates of the central tendency and dispersion of body size are presented in table 2 for both mated and unmated males at all five localities. No statistically significant differences in mean body size can be attributed to either a locality effect or mating status when means are used in a two-way analysis of variance with paired comparisons $(0 \cdot 25>\mathrm{P}>0 \cdot 10)$. Lack of normality and the presence of significant heteroscadasticity would obscure the significance of a more elaborate analysis of variance design involving within-cell replication using the lengths of individual beetles. Mean male adult body size is surprisingly constant across a wide area of the species range.

In order to test for stabilising selection for mating fitness we compute the ratio of the variance in body size of unmated to mated males at each locality. These F-ratios along with their level of statistical significance are also presented in table 2. If stabilising selection were occurring we would expect the variance in body size in unmated males to exceed that of mated males.

\section{TABLE 2}

Sample size $(\mathrm{N})$, mean $(\overline{\mathrm{Y}})$, variance $\left(\mathrm{S}^{2}\right)$, and range of elytral lengths for unmated and mated male Tetraopes populations as well as the variance ratio $(\mathrm{F})$.

\begin{tabular}{|c|c|c|c|c|c|c|}
\hline \multicolumn{2}{|c|}{ Locality No. } & $\mathcal{N}$ & $\bar{r}$ & $S^{2}$ & Range & $F$ \\
\hline 1 & $\begin{array}{l}\text { Unmated } \\
\text { Mated }\end{array}$ & $\begin{array}{l}35 \\
38\end{array}$ & $\begin{array}{l}8 \cdot 27 \\
8 \cdot 23\end{array}$ & $\begin{array}{l}0 \cdot 52 \\
0 \cdot 32\end{array}$ & $\begin{array}{l}6 \cdot 14-9 \cdot 29 \\
6 \cdot 43-9 \cdot 14\end{array}$ & $1.64 \dagger$ \\
\hline 2 & $\begin{array}{l}\text { Unmated } \\
\text { Mated }\end{array}$ & $\begin{array}{l}40 \\
40\end{array}$ & $\begin{array}{l}8 \cdot 18 \\
8 \cdot 18\end{array}$ & $\begin{array}{l}0 \cdot 28 \\
0 \cdot 28\end{array}$ & $\begin{array}{l}7 \cdot 00-9 \cdot 29 \\
7 \cdot 14-9 \cdot 43\end{array}$ & $1 \cdot 00$ \\
\hline 3 & $\begin{array}{l}\text { Unmated } \\
\text { Mated }\end{array}$ & $\begin{array}{l}40 \\
34\end{array}$ & $\begin{array}{l}8 \cdot 20 \\
8 \cdot 41\end{array}$ & $\begin{array}{l}0.57 \\
0.29\end{array}$ & $\begin{array}{l}5 \cdot 86-9 \cdot 71 \\
7 \cdot 29-9 \cdot 29\end{array}$ & $2 \cdot 00^{*}$ \\
\hline 4 & $\begin{array}{l}\text { Unmated } \\
\text { Mated }\end{array}$ & $\begin{array}{l}40 \\
32\end{array}$ & $\begin{array}{l}8 \cdot 29 \\
8 \cdot 45\end{array}$ & $\begin{array}{l}0.27 \\
0.36\end{array}$ & $\begin{array}{l}6 \cdot 86-9 \cdot 29 \\
7 \cdot 00-9 \cdot 43\end{array}$ & $0 \cdot 75$ \\
\hline 5 & $\begin{array}{l}\text { Unmated } \\
\text { Mated }\end{array}$ & $\begin{array}{l}34 \\
41\end{array}$ & $\begin{array}{l}8 \cdot 01 \\
8 \cdot 18\end{array}$ & $\begin{array}{l}0.52 \\
0 \cdot 27\end{array}$ & $\begin{array}{l}6 \cdot 57-9 \cdot 43 \\
6 \cdot 71-9 \cdot 00\end{array}$ & 1.94* \\
\hline
\end{tabular}

Note: all measurements are in $\mathrm{mm}, \dagger=P<0.075, *=P<0.05$. 
This is true in three of the five localities, confirming the earlier findings of Mason (1964) and Scheiring (1977). Since both the variances and the ranges of the unmated males exceed those of the mated males at these three localities, it appears that both excessively large and small beetles are at a disadvantage when acquiring mates. In two populations, however, there is no evidence at all for stabilising selection. Is this simply due to sampling error or is there a true variance among populations in the intensity of stabilising selection? An analysis of the data using Levene's test of equality of variances (Levene, 1960) reveals the variance in the size of mated males to be homogeneous across localities. In contrast, significant $(P=0.05)$ heterogeneity was found among localities for the variance in body size of unmated males. Essentially, this says that some populations contain more

TABLE 3

Sample size $(\mathrm{N})$, mean $(\overrightarrow{\mathrm{Y}})$, variance $\left(\mathrm{S}^{2}\right)$, and range of elytral lengths for unmated and mated female Tetraopes populations as well as the variance ratio $(F)$.

\begin{tabular}{|c|c|c|c|c|c|c|}
\hline \multicolumn{2}{|c|}{ Locality No. } & $\mathcal{N}$ & $\bar{r}$ & $S^{2}$ & Range & $F$ \\
\hline 1 & $\begin{array}{l}\text { Unmated } \\
\text { Mated }\end{array}$ & $\begin{array}{l}36 \\
38\end{array}$ & $\begin{array}{l}9 \cdot 33 \\
9 \cdot 21\end{array}$ & $\begin{array}{l}0.33 \\
0.41\end{array}$ & $\begin{array}{l}7 \cdot 71-10 \cdot 57 \\
7 \cdot 57-10 \cdot 29\end{array}$ & 0.80 \\
\hline 2 & $\begin{array}{l}\text { Unmated } \\
\text { Mated }\end{array}$ & $\begin{array}{l}29 \\
40\end{array}$ & $\begin{array}{l}8 \cdot 61 \\
8 \cdot 73\end{array}$ & $\begin{array}{l}0 \cdot 62 \\
0 \cdot 34\end{array}$ & $\begin{array}{l}6 \cdot 29-9 \cdot 86 \\
7 \cdot 14-9 \cdot 71\end{array}$ & $1.84 *$ \\
\hline 3 & $\begin{array}{l}\text { Unmated } \\
\text { Mated }\end{array}$ & $\begin{array}{l}34 \\
34\end{array}$ & $\begin{array}{l}9 \cdot 13 \\
9 \cdot 14\end{array}$ & $\begin{array}{l}0.33 \\
0 \cdot 50\end{array}$ & $\begin{array}{l}7 \cdot 86-10 \cdot 43 \\
7 \cdot 00-10 \cdot 43\end{array}$ & 0.66 \\
\hline 4 & $\begin{array}{l}\text { Unmated } \\
\text { Mated }\end{array}$ & $\begin{array}{l}28 \\
32\end{array}$ & $\begin{array}{l}8 \cdot 82 \\
8 \cdot 85\end{array}$ & $\begin{array}{l}0 \cdot 22 \\
0 \cdot 36\end{array}$ & $\begin{array}{l}8 \cdot 00-9 \cdot 86 \\
7 \cdot 43-9 \cdot 71\end{array}$ & 0.60 \\
\hline 5 & $\begin{array}{l}\text { Unmated } \\
\text { Mated }\end{array}$ & $\begin{array}{l}47 \\
41\end{array}$ & $\begin{array}{l}8 \cdot 76 \\
8 \cdot 81\end{array}$ & $\begin{array}{l}0.45 \\
0.54\end{array}$ & $\begin{array}{l}7 \cdot 57-10 \cdot 14 \\
7 \cdot 29-10 \cdot 29\end{array}$ & 0.83 \\
\hline
\end{tabular}

overall variation in body size than others and that the more variable populations possess individuals at a sufficiently large mating disadvantage that stabilising selection can be detected by statistical techniques. There is no geographical trend in population variability and, in fact, one finds both the presence and absence of stabilising selection in the two Illinois localities which are only two $\mathrm{km}$ apart.

Data for the females are presented in table 3. Analysis similar to that used for the males reveals a significant locality effect on mean body size $(\mathrm{P}<0.05)$ and, as above, no effect due to mating status. Females vary geographically in size whereas male mean size remains constant. It is interesting to note that the largest between-locality difference in mean female body size occurs between the two nearby Illinois populations.

Only one of the five populations shows evidence of stabilising selection for female body size. Again, the variance in the size of individuals found mating proved to be homogeneous among localities while the variance in the size of unmated individuals was found to be heterogeneous across localities $(\mathrm{P}<0.05)$. The occurrence of stabilising selection in only one of the five populations may indicate why Mason (1964) failed to detect this phenomenon for females. The relationship between variance in males and variance in females is unclear. Locality 1 showed stabilising selection for 
males and not females. The opposite was found at locality 2. If all intrapopulational variance was simply determined by the environment, one might expect the male and female variances to behave concordantly. The data here, however, suggest a more complex gender $\mathrm{X}$ locality interaction controlling the amount of intrapopulational variance in body size. The underlying cause of this remains obscure.

\section{Discussion}

The results presented here corroborate the findings by Mason (1964) and Scheiring (1977) that body size in Tetraopes tetraophthalmus is under strong stabilising selection with respect to mating fitness. That this phenomenon has been repeatedly detected for at least 14 years across a wide area of the species' range demonstrates the importance of body size to mating ability. Still, the physiological and/or behavioural mechanisms relating mating success to body size remain unclear and warrant further investigation. Equally unclear is the degree to which genetic variance is related to either intra- or interpopulational variance in body size. We do know, however, that much of the genetic variance detected electrophoretically in this species by Eanes et al. (1977) was highly partitioned between local populations sampled on Long Island, New York.

It may be possible to quantify the effects of this selection regime by calculating a fitness function for body size phenotypes. Under symmetric stabilising selection the fitness $\left(W_{i}\right)$ of an individual $\boldsymbol{Y}_{i}$ must be related to the deviation of that individual from the population mean $\bar{Y}$ so that

$$
W_{i}=f\left|Y_{i}-\bar{Y}\right|
$$

Of course the true function $f\left|Y_{i}-\bar{Y}\right|$ remains unknown but with a few biologically realistic assumptions, reasonable models can be readily constructed.

If the fitness of $Y_{i}$ were proportional to the local frequency of that phenotype as might be expected if a form of sexual selection favoured the most common type, then in a population roughly normally distributed for body size

$$
W_{i}=[S \sqrt{(2 \pi)}]^{-1} \exp \left[-\left(Y_{i}-\tilde{Y}\right)^{2} / 2 S^{2}\right]
$$

where $S$ and $S^{2}$ are the standard deviation and variance of that population and exp is the base of natural logarithms. Equation 2 is simply a form of the normal probability density function. Since fitnesses are generally expressed relative to the most fit type, in this case the mean phenotype $\bar{T}$, then

$$
W_{i(\mathrm{rel})}=\frac{[S \sqrt{(2 \pi)}]^{-1} \exp \left[-\left(Y_{i}-\bar{Y}\right)^{2} / 2 S^{2}\right]}{[S \sqrt{(2 \pi)}]^{-1} \exp \left[-(\bar{Y}-\bar{Y})^{2} / 2 S^{2}\right]}
$$

This reduces to

$$
W_{i(\mathrm{rel})}=\exp \left[-\left(Y_{i}-\bar{Y}\right)^{2} / 2 S^{2}\right]
$$

If the optimal mean phenotype is locally determined for each population, then eq. (4) can be used to measure the expected relative success of a migrant from a nearby phenotypically differing population. For example, 
mean size differs for females from nearby localities 1 and 2 (table 3). If a female of mean size and therefore maximum relative fitness in locality 2 migrated to locality 1 , her phenotype would no longer fall on the mean and her fitness would be reduced. Using values obtained from table 3 to evaluate eq. (4) a mean-sized female migrating from locality 2 to locality 1 would be expected to suffer a 25 per cent loss of relative fitness. A more general measure of the cost of migration would be the average loss of fitness expected among those individuals from population 2 available to migrate to population 1. Note that the average change in fitness is different from the change in fitness of an average-sized individual. The average change in fitness can be approximated by computing the change in fitness $\left(\Delta W_{i}\right)$ over the range of sizes represented in population 2 , should they migrate, and then calculating the average of these fitness differences $\left(\overline{\Delta W}_{i}\right)$ weighted by the expected frequencies of each size class in a normally distributed population. This can be done using the equation

$$
\overline{\Delta W_{i}}=\frac{\sum_{i=1}^{i=N}\left(W_{i, 2}\right)\left(W_{i, 2}-W_{i, 1}\right)}{\sum_{i=1}^{i=N} W_{i, 2}}
$$

where the fitnesses of $\mathcal{N}_{i}$ individuals are calculated in population $2\left(W_{i, 2}\right)$ and after migrating to locality $1\left(W_{i, 1}\right)$. Note that $W_{i}$ is a measure of both fitness and relative frequency. Evaluating eq. (5) with the data from table 3 reveals that females migrating from population 2 to population 1 would incur an average loss of fitness of 8 per cent.

Other reasonable fitness functions may be used to evaluate the fate of a migrant. A quadratic equation of the form

$$
W_{i(\mathrm{rel})}=1-\frac{\left(Y_{i}-\bar{Y}\right)^{2}}{K}
$$

is very similar to that used by O'Donald (1973) in a study of the Arctic Skua. The constant $K$ is determined here such that those individuals with body sizes beyond the range of sizes observed mating in the field have zero fitness. Equation (6) also predicts an 8 per cent average loss of fitness incurred by individuals migrating from locality 2 to 1 . A linear version of eq. (6)

$$
W_{i(\mathrm{rel})}=1-\frac{\left|Y_{i}-\bar{Y}\right|}{K}
$$

predicts a 10 per cent average decline in fitness.

If these fitness functions are reasonably close to the true fitness function, it appears that migration between populations exhibiting local differentiation in mean body size would be selected against by a lowering of the mating fitness of the migrants. Even if all variation in body size is environmentally determined, the work of Eanes et al. (1977) suggests that migrants would be likely to differ genetically at some loci from the population to which they immigrate. Therefore, stabilising selection within a population would tend to reinforce genetic differences between populations. This idea is similar in form to that expressed by Ringo (1977) in his discussion of the effect of 
sexual selection on the evolution of Hawaiian Drosophila where rapid phenotypic evolution and high rates of speciation are thought to be driven by geographically localised sexual selection.

Acknowledgements-I would like to thank Michael Wade, John Turner, Steven Teleky, and Felix Breden for their critical comments and Patricia LoBalbo for her invaluable field assistance.

\section{REFERENGES}

EANES, W. F., GAFFNEY, P. M., KOEHN, R. K., AND SIMON, C. M. 1977. A study of sexual selection in natural populations of the milkweed beetle Tetraopes tetraophthalmus. In Measuring Selection in Natural Populations, eds. F. B. Christiansen and T. M. Fenchel, pp 49-64. Springer-Verlag, Berlin, Heidelberg, New York.

LEVENE, H. 1960. Robust tests for equality of variances. In Contributions to Probability and Statistics, Essays in Honor of Harold Hotelling. I. Olkin and Others, eds., pp 278-292. Stanford Univ. Press, Stanford, Calif.

MASON, L. G. 1964. Stabilizing selection for mating fitness in natural populations of Tetraopes. Evolution, 18, 492-497.

O'DONALD, P. 1973. Frequency-dependent sexual selection as a result of variations in fitness at breeding time. Heredity, 30, 351-368.

RINGo, J. M. 1977. Why 300 species of Hawaiian Drosophila? The sexual selection hypothesis. Evolution, 31, 694-696.

SCHEIRING, J. F. 1977. Stabilizing selection for size as related to mating fitness in Tetraopes. Evolution, 31, 447-449. 